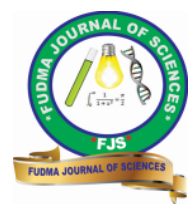

FUDMA Journal of Sciences (FJS)

ISSN online: $2616-1370$

ISSN print: 2645 - 2944

Vol. 4 No. 3, September, 2020, pp $382-388$

DOI: https://doi.org/10.33003/fjs-2020-0403-400

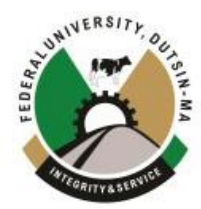

\title{
SPATIAL DISTRIBUTION AND LOCATIONAL IMPLICATIONS OF PUBLIC CONVENIENCES IN KANO METROPOLIS
}

\author{
${ }^{1}$ Auwal Haruna Ismail, ${ }^{* 1}$ Ahmad Said Abubakar, ${ }^{2}$ Nura Isyaku Bello and ${ }^{1}$ Ali Hussain \\ ${ }^{1}$ Geography Department, Aminu Kano College of Islamic and Legal Studies, Kano State, Nigeria \\ ${ }^{2}$ Geography Department, Kano University of Science and Technology Wudil, Kano State, Nigeria
}

Corresponding Author's email: asa99939@gmail.com, +2347054556454

\begin{abstract}
This study is aimed at examining the spatial distribution and locational implications of public conveniences in Kano metropolis. This research utilized mixed methods; where both qualitative and quantitative methods were used. Both primary and secondary source of data were used in this study. The primary data were obtained from field measurements while the secondary data were obtained from the Kano State Ministry of Environment, Kano State Urban Planning Development Authority (KNUPDA) as well as journals and previous theses. Materials used for this study include: Geo-positioning system (GPS) device (Garmin cx76 model) used for taking coordinates of the public conveniences (PCs). Computer software (Arc GIS 10.3) was also used in processing and analyzing of data generated from field. Availability sampling was used in administering questionnaires while purposive sampling was used for interview. The study find out that PCs are built rampantly without approval from appropriate government authority, which make them to build without complying with the standard rules and regulations. It is found that the distribution pattern of public PCs in Kano metropolis is mostly nucleated as they depend categorically on commercial activities as most of them are in motor parks or markets. This result also indicates that there is presence of air pollution and unsanitary condition due to poor drainage.
\end{abstract}

Keywords: Public Conveniences, spatial Distribution, Kano Metropolis.

\section{INTRODUCTION}

Globally, there are approximately 2.6 to 3 billion people without proper sanitation, with the worst situation in Southern Asia and sub-Saharan Africa, where the demand for sanitation is rising due to the growing population especially in the urban areas but with little attention to public convenience (WHO, 2012 and UNICEF, 2012). Public conveniences are often thought of as toilets and bathrooms that allow people to meet their sanitary needs in public places such as markets, and transport centres (Kolsky, 2006).

Public toilets have been defined by different authors; Shehu (2006) defined public toilets/conveniences as commercial sanitary facilities which mainly provide latrine and bathroom services to general public. Public toilets are places where one is obliged to ease oneself in unfamiliar surroundings among strangers of the same sex. Public facilities often have several toilets partitioned by stalls or cubicles. In some instances, a public toilet provides opportunity for bathing, defecation and urinals. In other cases, it provides only one service at a time; that is either bathing or defecation. Evidence of lack or poor public convenience abounds for the users as it is very common to see defecated materials and offensive odour emanating from urination especially in market places, drainage systems (gutter), open spaces, motor-parks etc. Almost 2.6 worldwide billion people do not have access to a toilet at all, and that includes a latrine, a bucket or a box (Global, 2011). Over one billion people are practising open defecation and the rest are using shared or poor sanitation facilities. If such trends continue, the world will miss the sanitation target by 600 million people (United Nations, 2007).
Hygienic public conveniences are located for the transient population in all areas of intense public activities such as markets, shopping areas, transport terminal, etc. The provision of properly managed functional public convenience facilities located in high-density areas such as markets, motor parks and open spaces will consolidate sanitary efforts of the State Government in respect to the mega-city concept and significant reduction in health-related problems (Asabia, 2011).

The rising numbers of public conveniences in the metropolitan area of Nigeria in general and Kano in particular have been recorded over the years. While such development appears to help in the drastic reduction of menaces like open defecation, and other unhygienic means of excreta management, it also contributes to many environmental problems due to their spatial distribution. While the number of public toilets is astronomically increasing in Kano metropolis for mainly commercial reasons, their spatial distribution does not guarantee accessibility across many parts of the area. It is common practice for people to answer the call of nature in the open field as a result of lack of public toilet facilities because they are more concentrated in some areas of commercial centres without consideration to their accessibility by the general population which results in a poor sanitary, health and environmental situation. Most of these conveniences are built in commercial areas like markets, motor parks etc. These affect their accessibility to people in some areas. People and government's main concern is for the income and revenue generated from the public convenience without regards to the implication on the general environment. 
In most parts of Kano metropolis, the public conveniences are located in different parts of the metropolis, but mainly concentrated in areas of high commercial activity such as markets and motor parks (Abba, 1997). People who are far away from their homes or those who have no such facilities in their residences or places of business or people with desperate needs mainly used them. Users pay a certain amount for the services offered.

There is the need for the provision of adequate sanitary facilities as well as their proper maintenance. Public toilets matter to everybody, regardless of their age, class, ethnic origin, gender, mental ability or physical ability. However, in recent times, most of these public toilets have been turned to another use different from the original intention. For example, some of these so-called sanitary facilities have been producing bad smell, which constitutes an environmental pollution to the areas involved. How their spatial distribution and locational implications leads to other critical environmental problems is what this research seeks to find out.

\section{MATERIALS AND METHODS}

Study Area

Kano Metropolis lies between Latitude $11^{\circ} 25^{\prime} \mathrm{N}$ and $12^{\circ} 47^{\prime} \mathrm{N}$ and Longitude $08^{\circ} 22^{\prime} \mathrm{E}$ and $08^{\circ} 39^{\prime} \mathrm{E}$ (Fig. 1). The Metropolis has eight LGAs i.e. Dala, Fagge, Nassarawa, Gwale, Tarauni, Kano Municipal, Kumbotso and Ungogo and is bordered by Minjibir LGA on the Northeast and Gezawa and Warawa LGA to the East, Dawakin Kudu LGA to the Southeast and Madobi and Tofa to the Southwest. It covers an area of approximately $500 \mathrm{~km}^{2}$.
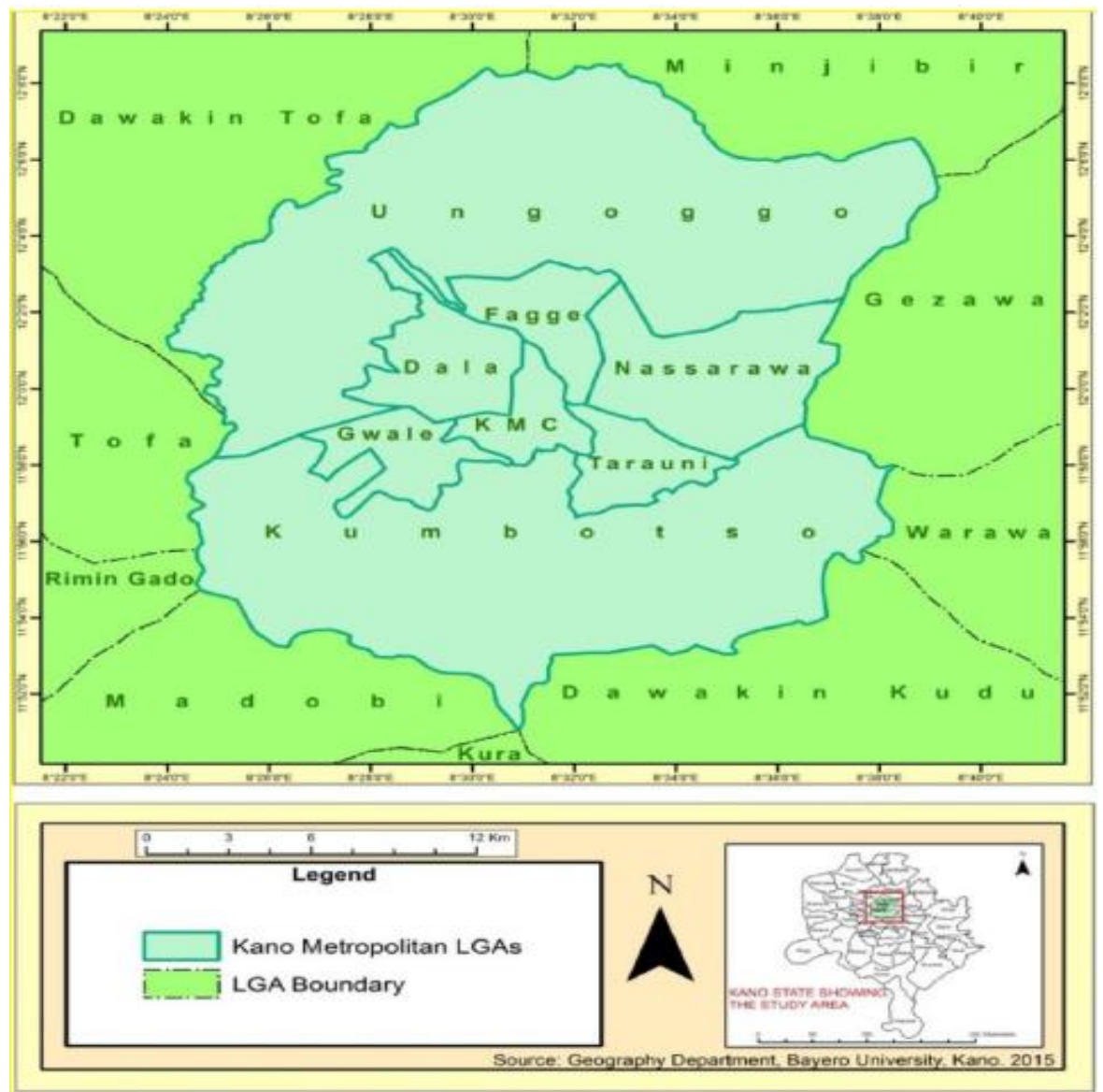

Fig.1: Study area of Kano metropolis

Kano region has the highest population in Northern Nigeria with over 14 million people (Abdulhamid, 2014). Kano metropolis has been the most important commercial and industrial nerve centre of Northern Nigeria attracting millions from all parts of the country and beyond (Nabegu, 2010). However, due to immigration and natural growth rate of 3.0 the population presently is estimated at 3.5 million, which is among the fastest growing cities in Nigeria. The metropolis has a population density of about 1000 people per $\mathrm{km}^{2}$ compared to the national average of 267 inhabitants per $\mathrm{km} 2$ (Nabegu, 2010). The area also has a large migrant worker population which has been increasing at the rate of 30 to 40 per cent per annum (UNDP 2004).

\section{TYPES OF DATA}

The research collected both qualitative and quantitative type of data as well as collecting both primary and secondary data for purpose of achieving the aim and objectives of the research.

Sources of data: Both primary and secondary source of data are used in this study. The primary data was from field measurements and from the operators and users of the public 
conveniences while the secondary data was from the Kano State Ministry of Environment, Kano State Urban Planning Development Authority (KNUPDA) as well as journals, articles and previous studies.

Materials used: Geo-positioning system (GPS) device (Garmin cx76 model) was used for taking coordinates of the public conveniences. This helped in mapping out the spatial distribution of the public conveniences. Coordinates of facilities that are not supposed to be located near the public conveniences like restaurants, hospitals, waterways, boreholes, just mentioned few were taken so as to spatially represent the existing environmental threat. Computer software (Arc GIS 10.3) was used in processing and analyzing of data generated from field.

\section{METHOD OF DATA COLLECTION}

The researchers used the following methods of data collection;

1. Reconnaissance survey: This was carried out to the public conveniences to know the state of the toilets and their location and to know the sampling method to be used.
2. Interview: Structured interviews were conducted with the owners' and operators of the public conveniences. This will help in achieving the objectives of the research

3. Questionnaires: This was administered to different people in the study area that uses the public conveniences. This helped to understand the accessibility as well as the environmental effect of the public conveniences in the study area.

\section{SAMPLING}

Due to the fact that the study area is geographically large for the research to cover it completely, some sampling procedures was adopted which enabled the researchers to get the reliable results.

Sampling Frame: According to the Kano State Urban Planning and Development Authority (KNUPDA, 2019), there are 107 public conveniences in the four Local governments of the study area (Gwale, Nassarawa, Dala and Kumbotso) in Kano metropolis. The geographical coordinates of all 107 public conveniences were mapped out and their spatial distribution in a map while some was used for selecting respondents for questionnaire administration.

Table 1: Sampling frame of the study area

\begin{tabular}{llll}
\hline S/N & Local Governments & No. Of Public Conveniences & No. Of Public Conveniences Selected \\
\hline $\mathbf{1}$ & Dala & 38 & 13 \\
$\mathbf{2}$ & Gwale & 11 & 5 \\
$\mathbf{3}$ & Kumbotso & 27 & 11 \\
$\mathbf{4}$ & Nassarawa & 31 & 12 \\
& Total & $\mathbf{1 0 7}$ & $\mathbf{4 1}$ \\
\hline
\end{tabular}

Source: KNUPDA, 2019

Sampling Methods and Size:For the purpose of this research, two sampling methods were used which are:

Availability sampling: Since the users of the public conveniences cannot be easily identified, this type of sampling technique was used to sample respondents for the administering of the questionnaire. Thus, the number of the respondents was chosen according to the number of public conveniences in the local governments of the metropolis.

Purposive sampling: This type of sampling was used to choose the most prominent public conveniences during reconnaissance survey andto interview the operators of those public conveniences in the study area.

Table 2: Sampling Size of the Study Area

\begin{tabular}{lllll}
\hline Sn & Local Govts. & $\begin{array}{l}\text { No. of } \begin{array}{c}\text { Public } \\
\text { Conveniences }\end{array} \\
\text { Questionnaires }\end{array}$ & $\begin{array}{c}\text { Sample Size } \\
\text { Interviews }\end{array}$ \\
\hline 1 & Dala & 38 & 65 & 13 \\
2 & Gwale & 11 & 20 & 5 \\
3 & Kumbotso & 27 & 55 & 11 \\
4 & Nassarawa & 31 & 60 & 12 \\
\hline & Total & $\mathbf{1 0 7}$ & $\mathbf{2 0 0}$ & $\mathbf{4 1}$ \\
\hline
\end{tabular}

\section{RESULTS AND DISCUSSIONS}

Based on the findings of this research, public conveniences in Kano metropolis are mostly located in commercial areas, mostly in markets and motor parks. This is because most of the users are casual patrons who are either short or long-term migrants far away from their homes. Others can also be found in places that are populated with high demand of toilets. One hundred and seven (107) major public conveniences were identified across the four (4)selected Local Government Areas of the Kano metropolis. Their pattern of distribution is mostly nucleated as they categorically depend on commercial factors for their location. This result negates the finding of Rabiu, ElGasim, and Al-Sheik (2018) which stated that the distribution of toilets is cluster. The coordinates of the PCs were taken to produce the map inFig. 2 . 


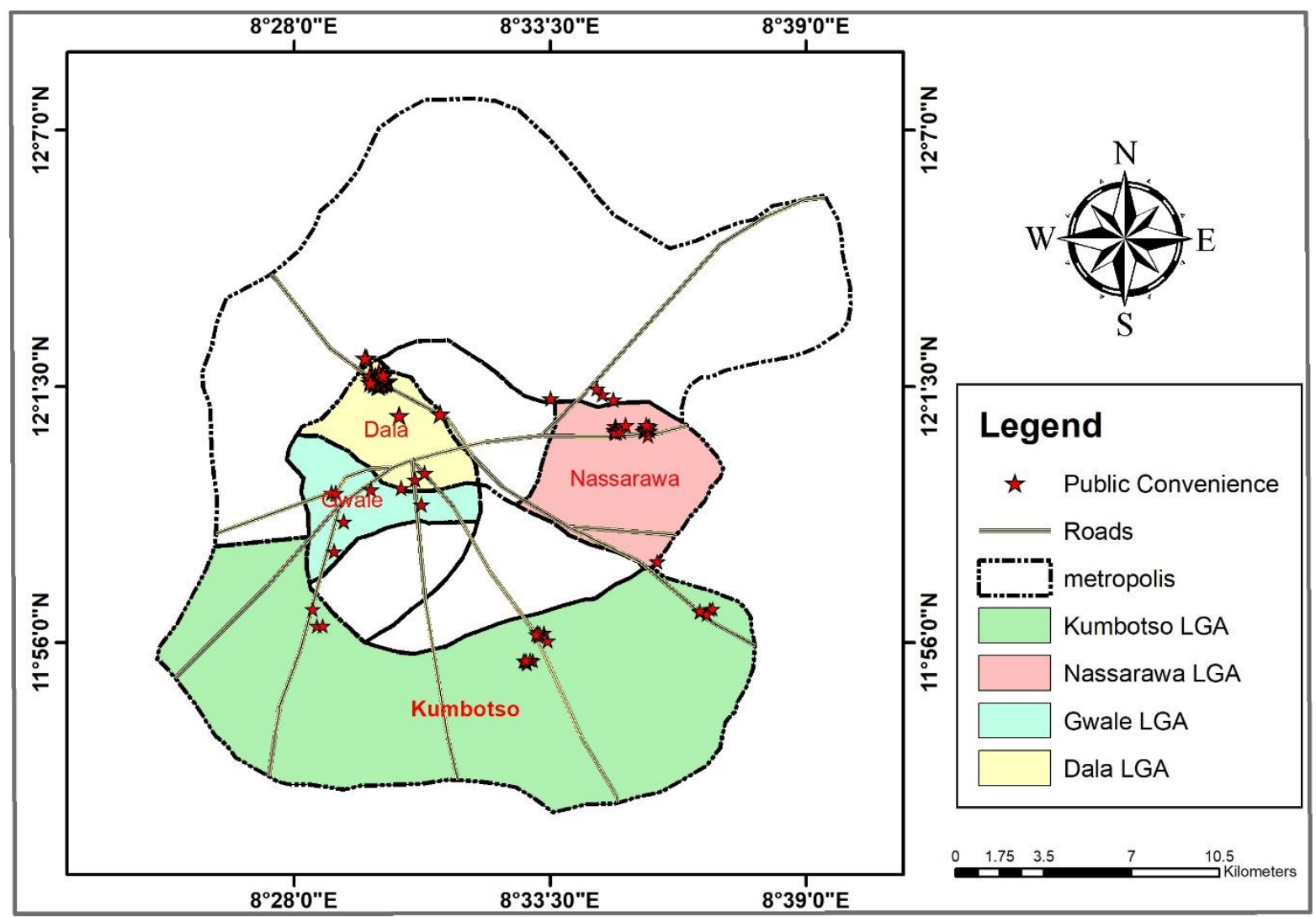

Source: Field work 2019

Fig. 2: Spatial Distribution of Public Conveniences in Some Part of Kano Metropolis

It can be observed from fig 2 that the pattern of the distribution of the PCs in the study area is mostly nucleated most significantly in Nassarawa, Kumbotso and Dala Local Governments. This is as a result of the presence of markets and motor parks. Almost all the PCs are located near or inside the markets and the motor parks. In Gwale Local Government however, the pattern of the distribution is sparse because of absence of commercial activities in the Area. This corroborates the finding of Abba (1997); Osumanu and Kosoe (2013); Désiréet al., (2015); which showed that most of PCs in Kano, Wa and Bamenda in Nigeria, Ghana and Cameroon respectively are located in commercial centers.

Locational Implication and Environment Threat of the Public Conveniences

The location of public convenience in any place can have an implication in the area. Based on the findings of this research, it was gathered that most of these PCs can affect the environment, people as well as other public and private properties in the area. PCs can help in spreading diseases among the users in an area. This is in line with what Désiréet al., (2015) found that there is spread of diseases due to poor PCs in Bamenda. The air can also be polluted through bad odor that can come from the toilets in the area. In addition, the soil can also be affected through mishandling of the excreta during evacuation. As most of these PCs have poor drainage network (Désiréet al., 2015), over flooding can also be a problem especially during rainy season.

\section{Land use Threat of Public Conveniences}

During field assessment, it was observed that PCs could serve as threat to many commercial land use activities. It was noticed that many of these PCs are located near many commercial activities as shown in the map of Fig 3 . 


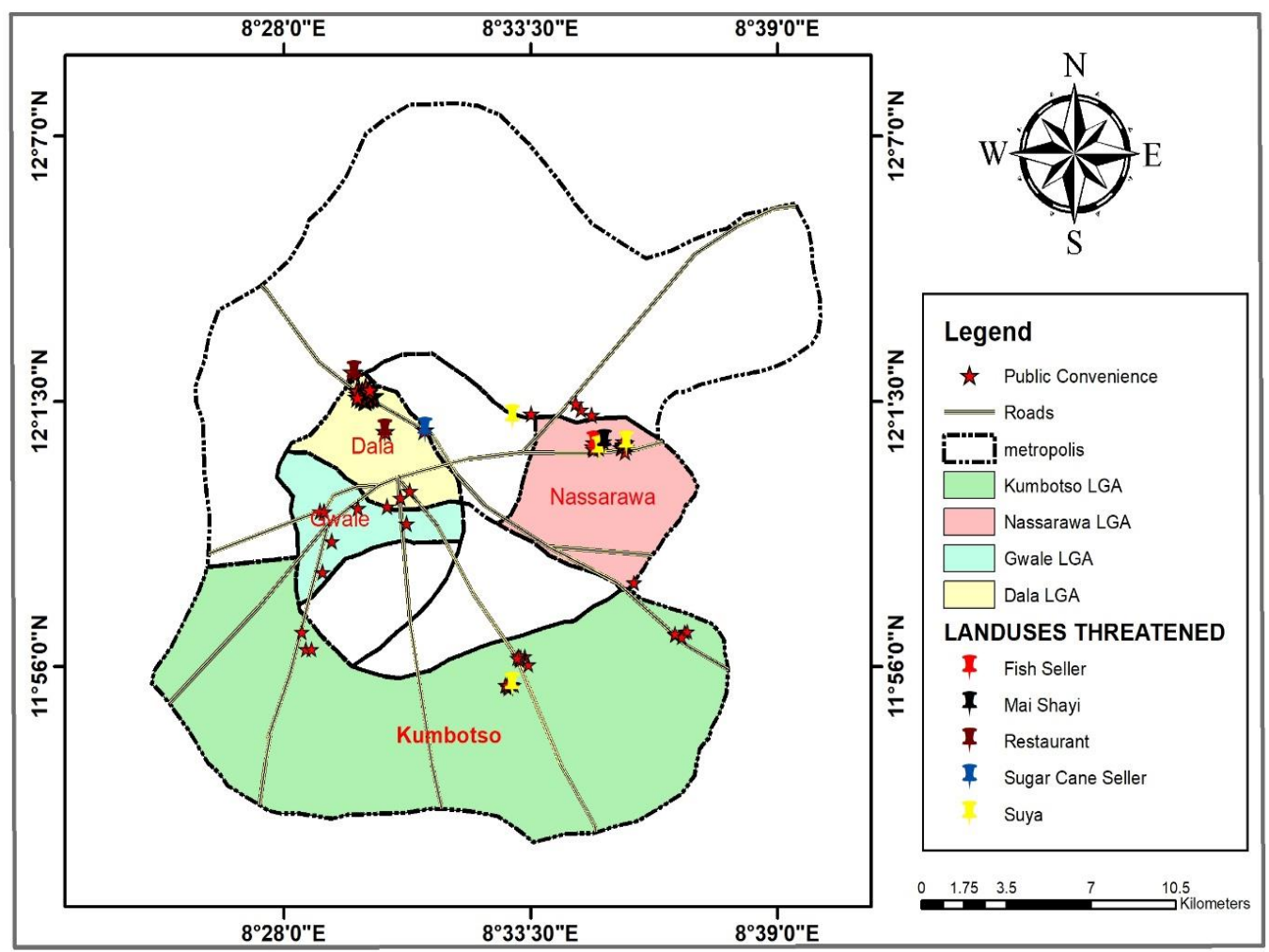

Source: Fieldwork 2019

Fig. 3: Land use threat of Public Conveniences

It can be observed from the above map that many of these PCs are built near restaurants, fish sellers, sugarcane sellers, and fura da nono shops, etc. (plate 1) This can pose a threat to the hygiene of these commercial activities. Many people will not patronize these restaurants as a result of the closeness to the PCs because of the bad odour that will come from the PCs and fear contracting diseases from eating the food in such location.

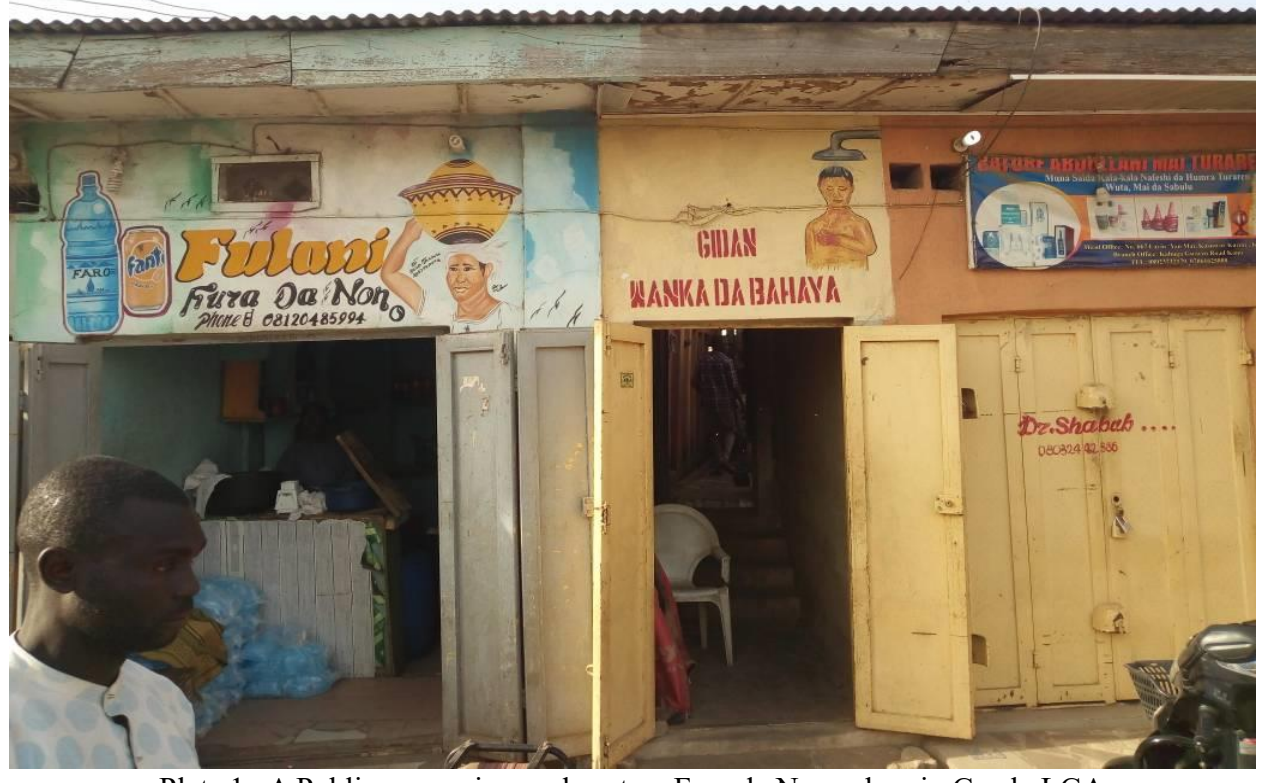

Plate 1: A Public convenience close to a Fura da Nono shop in Gwale LGA 


\section{Concentration of Public Conveniences}

The availability of public convenience in Kano metropolis varied with respects to the four Local Governments Areas studied. Dala and Nassarawa are classified as areas with high concentration of public conveniences, Kumbotso as area with medium concentration and Gwale as area of low concentration of the PCs.

The reason for this is that Nassarawa and Dala local governments are far more commercially oriented than Kumbotso and Gwale. Furthermore, according to the 2016 national census, the population of Dala almost triples that of Gwale LGA whose majority of territory falls within the old conservative city center where services like PCs would hardly be relevant. Kumbotso, which is largely outside the city center, has relatively low population and fewer commercial activities as reason for low concentration of PCs.

\section{FACTORS THAT AFFECT THE LOCATION OF PUBLIC CONVENIENCES}

Most $(39.27 \%)$ PCs owners claimed that the primary factor they consider when locating public toilets is the proximity to commerce that is either in markets or motor parks. Out of the 107 PCs identified in the study area, only 16 are not located in either market or motor parks. This made the research to conclude that the major reason behind this location is the drive for market without consideration to accessibility to users.
However, in the course of gathering data in this research, it was observed that many other factors can influence the location of the PCs. These factors are:

Population: this can be a major factor in locating any PC. They are built in areas with high concentration of population in order to have high number of people that will patronize them. Kano metropolis being an area that is blessed with high population density makes the owners use that as an advantage to build many public toilets.

Concentration of Migrants: Kano metropolis attracts many migrants from within the state and neighboring state that engage in many economic activities like shoe making, water vendors and nail cutters etc. These also make it a necessity to provide these migrants with public toilets for their day-to-day use. Many of those patronize these toilets are mostly migrants and people that a faraway from their respective houses.

Road Junction: this is another factor that is considered in locating public conveniences. Road junctions which can serve as a temporary bus stop also attract a number of people either as hawkers or travelers, andpublic conveniences can be located here for the usage of the people.

Table 3: Factors that necessitate the location of public convenience

\begin{tabular}{lll}
\hline Response & Respondents & Percentage (\%) \\
\hline Concentration of migrants & 46 & 24.0 \\
Proximity to commerce & 75 & 39.27 \\
Convenience & 20 & 10.47 \\
Proximity to user & 50 & 24.18 \\
TOTAL & $\mathbf{1 9 1}$ & $\mathbf{1 0 0}$ \\
\hline
\end{tabular}

Source: Questionnaire Survey, 2018

From the above 46 of the respondents which represents $24.08 \%$ are opined that concentration of migrants necessitate the location of PC while 75 of the respondent which represents $39.27 \%$ believe that proximity to commerce necessitate its location, 20 of the respondents which represents $10.47 \%$ believe that convenience to people necessitate its location while 50 of the respondents which represent $26.18 \%$ are of the opinion that proximity to users are the main factors that necessitate the location of the public convenience.

\section{CONCLUSION}

Public conveniences are not evenly distributed in Kano metropolis as this study revealed. They are more concentrated in commercial areas as the main aim of the owners is for profit making without regards to people accessibility and their locational implications. The Pcs are built rampantly without approval of any government authority which make them to be built without complying to the standard rules and regulations which can cause an adverse effect to the nearby people and to the environment. As water supply is a general problem in Kano metropolis, it tends to affect the smooth running of these PCs since there is absence of reliable water that can be used to wash the toilets, baths etc. this create a massive problem to the users of these PCs.

\section{REFERENCES:}

Abba, M. (1997). Towards Effective Management of Public Conveniences in Kano Municipality. Unpublished PGD Project, Bayero University, Kano, Nigeria.

Abdulhamid, A. (2014) 'Drainage, Hydrology and Water Resources of Kano Region'. Chapter three In the book: Kano, Environment, Society and Development (Edited by A.I Tanko and S.B Momale).

Areo, I.O., Sako, K.C. and Lucky, E.(2019). Assessment of Public Restroom Distribution Pattern in Gwarinpa, Federal Capital City; (FCC) Abuja. Confluence Journal of Environmental Studies 13 (1):12-22

Asabia, A. (2010).Making a Clean Change; Women run Facilities Promote Health and Sanitation, www.metamorphosis-nigeria.org (accessed on 6 December, 2011).

Désiré, S.S.M., Aimé, A.S., Landry, N.S.J., Manga J.M.V. M., Babah, Y.G., Soleil, B.R.A. (2015). The Use of Public Toilets 
and Health Risks: The Case of Bars, Snacks and Restaurants in the Bamenda Ii Municipality. International Journal of Innovative Science, Engineering \& Technology 2(10): 332-360

Global Citizen. (2011); Introduction to the Crisis of Clean Water and Sanitation. Retrieved on $1^{\text {st }}$ September, 2020 from http://www.globalcitizen.org/content.aspx?id=9c09b47b-8274$\underline{451 \mathrm{~d} 8 \mathrm{~b} 7 \mathrm{a} 408 \mathrm{ce} 9 \mathrm{ffd} 9 \mathrm{ec}}$

Kano state Urban Planning Development Authority (KNUPDA, 201). Guideline for establishment of public convenience.

Kolsky, P. (2006). Opening Remarks for the "Public and Community Toilets: Lessons and Ideas from Experience in Nairobi, Delhi, Mumbai, and Liuzhou", Video Conference held October 3-4, 2006, the World Bank.

Nabegu A.B (2010). An Analysis Solid Water Management in Kano Metropolis, Journal of Human Ecology, 31(2): 111

Osumanu, I.K. and Kosoe, E.A (2013). Where do I answer nature's call? An assessment of accessibility and utilisation of toilet facilities in Wa, Ghana. Ghana Journal of Geography 5(1): 17-31
Rabiu, M, El-Gasim, G. A. and Al-Sheik, A. (2018). Spatial Pattern of Insanitary Toilet Facility in Nigerian States and Federal Capital Territory Using GIS Pattern Analysis. Journal of Geography, Environment and Earth ScienceInternational15(1): 1-10

Shehu, M. (2006). "An Appraisal of Public Conveniences in Kano Metropolis, Nigeria." An M.Sc. Thesis submitted to the Department of Building. ABU, Zaria.

UNDP (2004): Municipal Solid Waste Management in Developing Countries; A Policy Frame Work Geneva. Technical Paper, 12 Geneva; UNDP

UNICEF (2012) Progress on Sanitation and drinking water. 2012 update, WHO Press Switzerland

United Nations (2007): The Millennium Development Goals Report. New York: United Nations 58

WHO (2012) Progress on Sanitation and drinking water. 2012 update, WHO Press Switzerland

(C)2020 This is an Open Access article distributed under the terms of the Creative Commons Attribution 4.0 International license viewed via https://creativecommons.org/licenses/by/4.0/ which permits unrestricted use, distribution, and reproduction in any medium, provided the original work is cited 